Short Communication

\title{
Cheap and Eco-Friendly Synthesis of Polyaniline and Performance of Aqueous Zn-polyaniline Battery
}

\author{
Yanlin Li, Haotian Wang, Tiandie Yu, Jiaxin Li, Jinqing Kan* \\ Department of Chemical Engineering and Pharmacy, Guangling college, Yangzhou University, \\ Yangzhou, 225002, China. \\ *E-mail: jqkan@163.com,jqkan@yzu.edu.cn
}

doi: $10.20964 / 2020.07 .61$

Received: 2 March 2020 / Accepted: 29 April 2020 / Published: 10 June 2020

\begin{abstract}
Polymerized from the abundant and cheap aniline monomer, polyaniline has high stability in air, water and other media, good redox reversibility, and advantages of easy synthesis, which has been widely studied in recent years. In this paper, a new synthesis method of polyaniline by adding trace ammonium persulfate into the conventional system of $\mathrm{H}_{2} \mathrm{O}_{2}-\mathrm{Fe}^{2+}$ was used, which achieves a yield of polyaniline higher than $90 \%$ in less than 5 hours. More importantly, the waste solution generated in the processes of filtering and washing of polyaniline products can be recovered and recycled for subsequent synthesis, which avoids the problem of waste liquid treatment existed in conventional synthesis route. The infrared absorption peaks of the as prepared polyaniline are consistent with that synthesized in conventional $\mathrm{H}_{2} \mathrm{O}_{2}-\mathrm{Fe}^{2+}$ system. The specific capacity of the zinc-polyaniline aqueous battery assembled by the polyaniline is as high as $80 \mathrm{mAh} \cdot \mathrm{g}^{-1}$ when charged and discharged at $0.1 \mathrm{C}$. The coulomb efficiency is higher than 93\% when the battery is charged and discharged over 800 times at $0.3 \mathrm{C}$. It shows that the battery has good redox reversibility and good charge discharge cycle performance. This work provides a low cost synthesis route of polyaniline, which inspires the further development of zinc polyaniline battery for commercial application.
\end{abstract}

Keywords: polyaniline hydrogen peroxide ferrous sulfate $\cdot$ cheap and eco-friendly synthesis $\cdot$ high yield

\section{$\underline{\text { FULL TEXT }}$}

(C) 2020 The Authors. Published by ESG (www.electrochemsci.org). This article is an open access article distributed under the terms and conditions of the Creative Commons Attribution license (http://creativecommons.org/licenses/by/4.0/). 